\title{
OPTIMAL PARAMETERS FOR ArF LASER MICROMACHING OF SiC AND PZT
}

\author{
Jean-Philippe Desbiens and Patrice Masson \\ Department of Mechanical Engineering, Université de Sherbrooke \\ Sherbrooke, QC CANADA
}

\begin{abstract}
The ablation process has been characterized for a number of laser sources in silicon ( $\mathrm{Si}$ ) micromachining. However, very few results can be found in the literature for excimer laser technology at $193 \mathrm{~nm}$ on $\mathrm{Si}$ and even fewer for other materials. Moreover, most of the work has previously been reported for quasi-static conditions, not taking into account the movement of the sample relative to the laser beam. In order to globally consider the relative velocity of the sample with respect to the laser beam, a metric called Nppd (number of laser pulses deposited per beam diameter) is first defined in this work. Experimental results are presented to evaluate the micromachining performance of the excimer laser for three different materials ( $\mathrm{Si}, \mathrm{PZT}$ and Pyrex). Optimal parameters are obtained and then used to micromachine silicon carbide ( $\mathrm{SiC})$, in addition to the previous materials.
\end{abstract}

\section{INTRODUCTION}

Laser micromachining is currently being used to complement photolithography techniques in the prototyping of a number of MEMS devices [1]. In particular, the $193 \mathrm{~nm}$ ArF excimer laser allows to micromachine materials by ablation with minimal thermal effect thanks to a short pulse width $(<20 \mathrm{~ns})$. The photon energy at $193 \mathrm{~nm}(6.4 \mathrm{eV})$ is in fact higher than that at higher wavelengths $(5 \mathrm{eV}$ with a $\mathrm{KrF}$ laser at $248 \mathrm{~nm}$ ). This allows to more easily destroy the intermolecular bonds within the material. However, the power delivered by the ArF laser tends to be slightly less than that of $248 \mathrm{~nm}$ lasers so that the overall micromachining efficiency is reduced. Details in the order of a few microns can be fabricated using laser micromachining. New generations of MEMS integrating a number of thick layers $(>5 \mu \mathrm{m})$ made of different materials such as glass, silicon $(\mathrm{Si})$, silicon carbide $(\mathrm{SiC})$ and piezoceramics (PZT) could benefit from laser micromachining techniques. These materials do not find widespread applications due to limitations in fabrication processes. Moreover, laser micromachining offers the flexibility to fabricate $3 \mathrm{D}$ structures [2, $3,4]$.

Very few quantitative results can be found in the literature on the interaction of the different parameters involved in excimer laser micromachining for workpiece dragging. Most of the references concentrate on static processes (e.g. hole drilling, mask patterning). Li [4] has however shown that experiment design methods can be used to optimize the parameters for Si. It appears that since considerable effort is devoted for the calibration of the parameters, very limited data is available on this. Glass (Pyrex, fused silica) and polymers are the most common materials micromachined using lasers $[\mathbf{2}, \mathbf{6}, \mathbf{7}, \mathbf{8}, \mathbf{9}, \mathbf{1 0}]$. Ink jet printer nozzles are an example of devices manufactured by excimer laser micromachining.

It is the purpose of this work to present an experimental parametric study of ArF excimer laser micromachining of Si, PZT, Pyrex and SiC at $193 \mathrm{~nm}$, taking into account the displacement of the sample.The results will help define optimal parameters for the micromachining of SiC, Pyrex and PZT which are becoming common components of MEMS.

\section{THEORY}

\section{A. Laser-matter interaction}

Two phenomena are involved in the ablation process using a laser beam: i) direct photochemical bond breaking by the absorption of photons and ii) melting of the material by thermal conduction in the material structure (photothermal process). Part of the beam energy is reflected at the surface of the sample. Following the ionisation of the material surface (photochemical process), a plasma creates an increase of the local pressure which helps vaporize solid or melted debris (Figure 1).

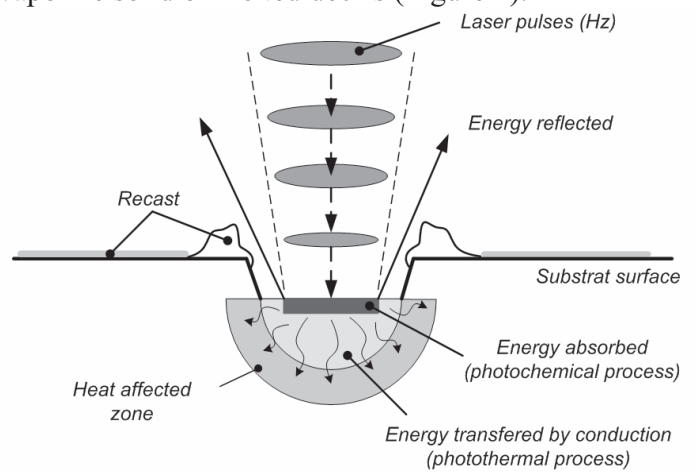

Figure 1. Laser-matter interaction of a pulsed laser beam.

The debris are then deposited in various shapes around the work zone. The material usinability is dependent upon their optical and mechanical properties such as reflectivity, thermal conduction, optical absorption, melting temperature,... However, laser ablation allows to micromachine any material, as opposed to standard photolithographic microfabrication techniques, even if $\mathrm{Si}$ and metallic materials are poor candidates. For $\mathrm{Si}$, wet etching techniques or plasma techniques (DRIE) are to be preferred.

\section{B. Parameters for pulsed laser ablation process}

There are many important geometrical relations between machining parameters when using laser ablation with the workpiece dragging technique. The main following parameters are to be considered:

- linear machining velocity $[V](\mu \mathrm{m} / \mathrm{s})$;

- laser repetition rate $[f](\mathrm{Hz})$;

- beam size : diameter $[D](\mu \mathrm{m})$;

- energy distribution over the beam area: Gaussian or uniform following homogenization;

- fluence $[F]\left(\mathrm{J} / \mathrm{cm}^{2}\right)$;

- number of passages $[N]$;

- beam focalization angle $\left(3^{\circ}\right)$

From these parameters, relations can be extracted to predict the resulting micromachined geometries. (Figure 2).

From Figure 2, for a laser beam with a diameter of $15 \mu \mathrm{m}$ pulsed at a rate of $3 \mathrm{~Hz}$ and travelling at $15 \mu \mathrm{m} / \mathrm{s}$ with respect to the sample, the depth of the micromachined trench can be predicted. Assuming an ablation rate of $5 \mu \mathrm{m} /$ pulse, a trench of 15 $\mu \mathrm{m}$ depth is micromachined with an angle of $45^{\circ}$. 


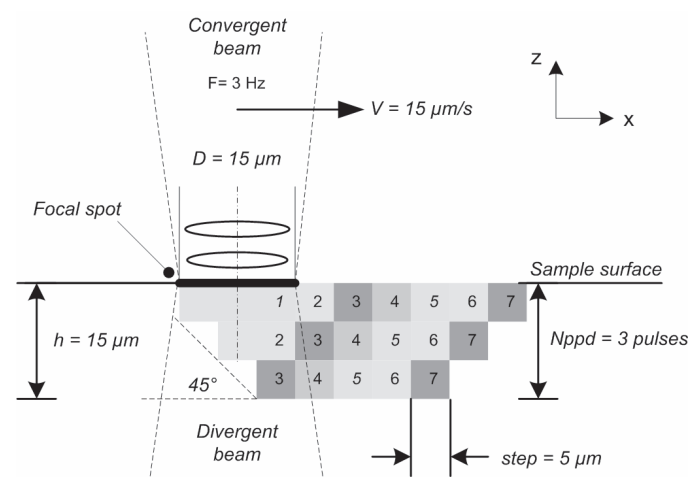

Figure 2. Geometrical parameters for material ablation using pulsed focalized excimer laser.

In order to globally consider the relative velocity of the sample with respect to the laser beam, it is thus possible to define a metric called Nppd (number of laser pulses deposited per beam diameter):

$$
\text { Nppd }=N^{*} f^{*} D / V \quad \text { [shots] }
$$

By encompassing $N, f, D$ and $V$, the $N p p d$ parameter provides a global parameter taking into account the coupling between these parameters. The etch rate $(\mu \mathrm{m} / \mathrm{shot})$ can be determined from the Nppd given that one is able to measure the final depth of cut after $N$ passages for constant process parameters:

$$
\text { Etch } \mathrm{rate}=\mathrm{h} / \mathrm{Nppd} \quad[\mu \mathrm{m} / \mathrm{shot}]
$$

Finally, the shape of the beam area and its energy distribution will also influence the cutting profile. For example, with a circular beam and workpiece dragging technique, the pulse overlap will be more important in the center of the trajectory. The cutting profile would then be a semi-elliptic shape. The beam focalization angle also affects slightly the cutting profile since the fluence decreases as beam area increases.

\section{EXPERIMENTAL SETUP}

\section{A. Laser micromachining system}

The four-axis (XYZR) laser micromachining system is shown in Figure 3. The system uses an X-imer 300 ArF excimer laser (MPB Communications Inc.) which generates pulses with $5 \mathrm{~ns}$ width. The maximum energy is around $6.5 \mathrm{~mJ}$ and the highest repetition rate is $300 \mathrm{~Hz}$.

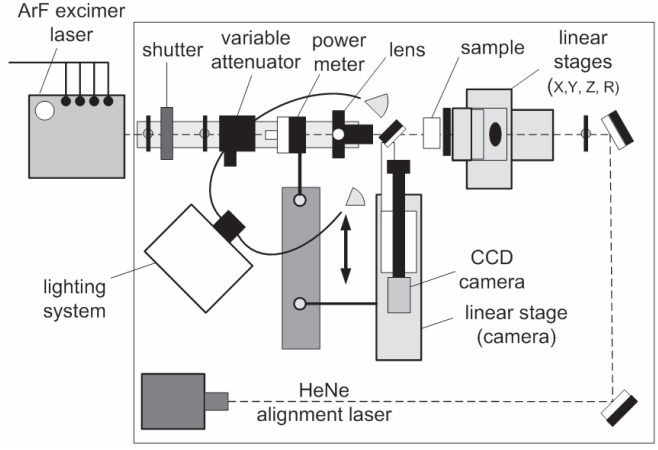

Figure 3. Four-axis laser micromachining system.

The $4 \mathrm{~mm} \times 4 \mathrm{~mm}$ Gaussian beam is conditioned with a circular mask of $3 \mathrm{~mm}$ diameter. The beam is then collimated and focused with appropriate lenses. A variable attenuator is used to modulate beam energy. The diverging portion of the beam is used to ablate the material. By positioning adequately the sample with the $\mathrm{Z}$ axis, the machining tool diameter can be adjusted. Typical tool diameters can vary between $10 \mu \mathrm{m}$ and $150 \mu \mathrm{m}$ and the fluence used never exceed $100 \mathrm{~J} / \mathrm{cm}^{2}$.

\section{B. Experimental procedure}

In order to evaluate optimum parameters for laser ablation of some selected materials ( $\mathrm{Si}$, Pyrex, PZT and $\mathrm{SiC}$ ), a series of seven experiments were realized, as shown in Table I.

\begin{tabular}{|c|l|l|}
\hline Test & Parameter & Materials \\
\hline 1 & Fluence, $F\left(\mathrm{~J} / \mathrm{cm}^{2}\right)$ & Si, Pyrex, PZT and $\mathrm{SiC}$ \\
\hline 2 & Repetition rate, $f(\mathrm{~Hz})$ & $\mathrm{Si}$, Pyrex, PZT \\
\hline 3 & Velocity, $V(\mu \mathrm{m} / \mathrm{s})$ & $\mathrm{Si}$, Pyrex, PZT \\
\hline 4 & Number or passages, $N$ & $\mathrm{Si}$, Pyrex, PZT \\
\hline 5 & Beam diameter, $D(\mu \mathrm{m})$ & PZT \\
\hline 6 & Focal spot displacement & Pyrex \\
\hline 7 & $\begin{array}{l}\text { Trajectory overlap for } \\
\text { milling demonstration }\end{array}$ & Pyrex \\
\hline
\end{tabular}

Table I. List of conducted tests.

For each test and material, 16 cuts were made in order to limit the number of experimental measurements. Imaging of each laser cut is obtained using an optical microscope at 20x. Measurements for each cut are shown in Figure 4 and were estimated $( \pm 3 \mu \mathrm{m})$ from the image using National Instruments Vision Builder.

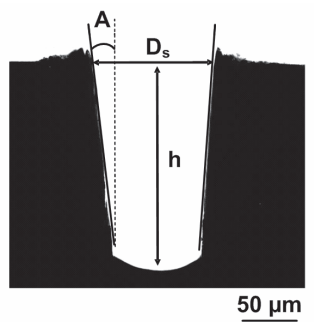

Figure 4. Typical measurements extracted from sample image.

Criteria for laser micromachining process optimization are:

- ablation time : a metric called $t$ was define as the time to cut a $100 \mu \mathrm{m}$ line with a depth of $50 \mu \mathrm{m}$ at a particular speed $(V)$ in reference with the measured ablation depth $(h)$ :

$$
t=100 \mu m * 50 \mu m /(V * h) \quad[s]
$$

- acceptable edge quality and minimum recast materials;

- minimum taper angle A;

- high value of etch rate ( $\mu \mathrm{m} / \mathrm{shot})$.

Each test is intended to help identify optimal values for each parameter to incrementally calibrate the process (from one test to another, cascading approach). Second order interaction between parameters was neglected. The parameters for Test 1 were fixed to known working values: $F=1-80 \mathrm{~J} / \mathrm{cm}^{2}, f=50 \mathrm{~Hz}, V=25 \mu \mathrm{m} / \mathrm{s}, N=2$, $D=35 \mu \mathrm{m}$. Laser fluence threshold ranges from $0.5 \mathrm{~J} / \mathrm{cm}^{2}$ (for Pyrex) to $1 \mathrm{~J} / \mathrm{cm}^{2}$ (for $\mathrm{SiC}$ ) according to preliminary observations. Pressurized air is used to clean the ablation zone.

\section{RESULTS}

Test 1 through Test 4 revealed that a proper choice of parameters can lead to better laser micromachining results (Figure 5). From these curves and visual observation of the cut profile, the optimal range identified for the process parameters are given below:

- Fluence $(F)$ : etch rate rapidly increases for fluence range of 1 to $40 \mathrm{~J} / \mathrm{cm}^{2}$. It was observed (Figure $5 \mathrm{a}$ ) that to avoid 
thermal damage for Pyrex, fluence must be limited to 10 $\mathrm{J} / \mathrm{cm}^{2}$.

- Repetition rate $(f): f$ can be fixed to more than $100 \mathrm{~Hz}$ for Pyrex and PZT without etch rate reduction. The frequency is limited to $100 \mathrm{~Hz}$ by the laser performance which drops rapidly for higher values (Figure $5 b$ ).

- Velocity of sample $(V)$ : velocity can be set higher than 150 $\mu \mathrm{m} / \mathrm{s}$ since etch rate reach a constant value from $V=50 \mu \mathrm{m} / \mathrm{s}$ as seen in Figure $5 \mathrm{c}$.

- Number of passages $(N)$ : up to 32 passages without significative reduction in etch rate for Pyrex and PZT (Figure $5 d)$.
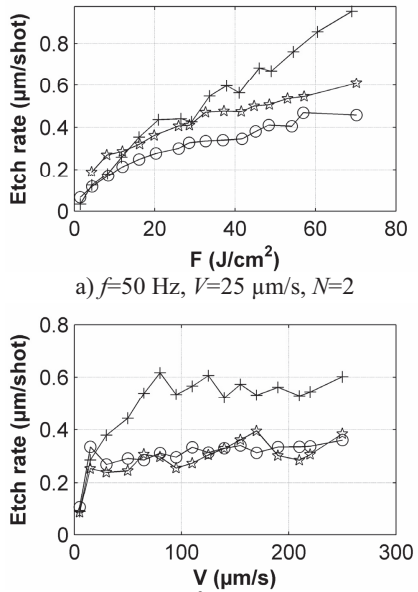

c) $F=21 \mathrm{~J} / \mathrm{cm}^{2}, f=100 \mathrm{~Hz}, N=2$ a) $f=50 \mathrm{~Hz}, V=25 \mu \mathrm{m} / \mathrm{s}, N=2$

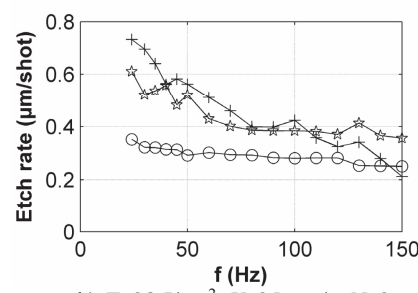

b) $F=28 \mathrm{~J} / \mathrm{cm}^{2}, V=25 \mu \mathrm{m} / \mathrm{s}, N=2$

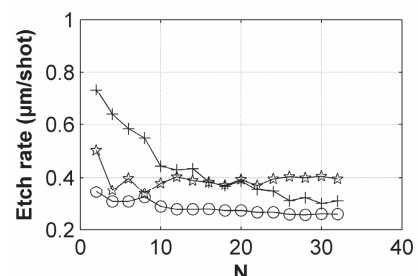

d) $F=28 \mathrm{~J} / \mathrm{cm}^{2}, f=100 \mathrm{~Hz}, V=170 \mu \mathrm{m} / \mathrm{s}$

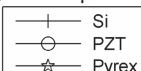

Figure 5. Ablation rate per laser pulse for Si, PZT and Pyrex, as a function of the fluence (a), the repetition rate (b), the velocity of the sample (c) and the number of passages (d).

Test 1 was conducted a second time with optimal parameters on all previous materials, in addition to a-SiC. As shown in Figure $6 \mathrm{a}$, etch rate has not changed significantly after optimization even if sample velocity and repetition rate are increased. Even if etch rate values for $\mathrm{SiC}$ seem to be the lowest, the laser cut profile for amorphous $\mathrm{SiC}$ is clean and has a flat bottom (Figure 6c).

For an optimized process, thin layers of material are ablated at each passage. Typical ablation rate varying from $5 \mu \mathrm{m}$ to $10 \mu \mathrm{m}$ per passage can be achieved with fluence around $10 \mathrm{~J} / \mathrm{cm}^{2}$ and optimal parameters $(f=100 \mathrm{~Hz}, V=170 \mu \mathrm{m} / \mathrm{s})$. Ablation time $t$ is typically reduced by two for all materials after calibration (see Figure $6 \mathrm{~b}$ for Pyrex) and less recast is observed in the ablation area. It is important to note that the diameter and wall angle measurements are slightly different for each material tested. Si cut wall are also less uniform than other materials tested and recast material can be clearly see under microscope or SEM images.

Other important results arise from the complementary tests:

- Test 5, beam diameter: the laser beam diameter can be easily adjusted via focal point displacements. The etch rate is velocity and diameter dependent by the Nppd metric defined previously. The etch rate decreases with an increase in the beam diameter but not linearly as expected. Further work would be required to understand why this is not observed for PZT (Figure 6d).

- Test 6, focal spot displacement: by moving the focal spot in order to follow depth penetration during ablation, no etch rate variation is observed for a single cut with multiple passages.

- Test 7, trajectory overlap: in order to verify if laser milling leads to good geometrical results, Test 7 consisted in two laser cuts side by side with a varying overlap (0-80\%). Results showed that with minimal overlap $(<5 \%)$ and a circular laser beam, it is possible to ablate a cut profile with flat bottom on Pyrex. To ensure good interface between cuts, focal spot displacement was used. This result was extrapolated to laser milling of a rectangular cavity in Pyrex (Figure 7).

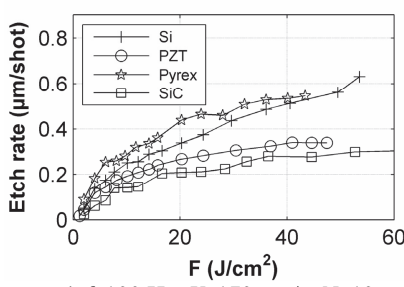

a) $f=100 \mathrm{~Hz}, V=170 \mu \mathrm{m} / \mathrm{s}, N=10$.

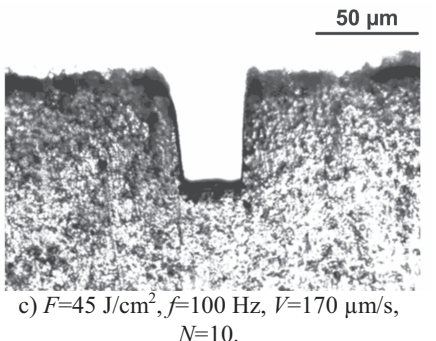

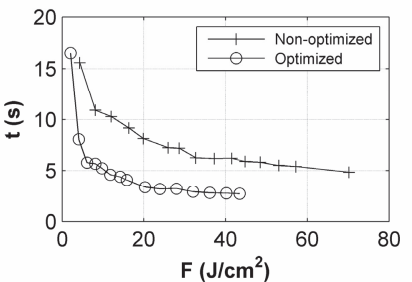

b) Non-optimized: $f=50 \mathrm{~Hz}, V=25 \mu \mathrm{m} / \mathrm{s}$, $N=2$. Optimized: $f=100 \mathrm{~Hz}, V=170 \mu \mathrm{m} / \mathrm{s}$, $N=10$.

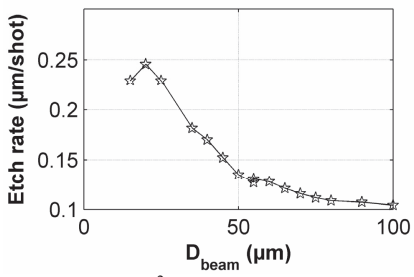

d) $F=10 \mathrm{~J} / \mathrm{cm}^{2}, f=100 \mathrm{~Hz}, V=170 \mu \mathrm{m} / \mathrm{s}$, $N=12$.
Figure 6. Results from optimization: ablation rate per pulse (a), ablation time for Pyrex for non-optimized and optimized processes (b), cut in a-SiC (c), ablation rate per pulse as a function of beam diameter for PZT (d).

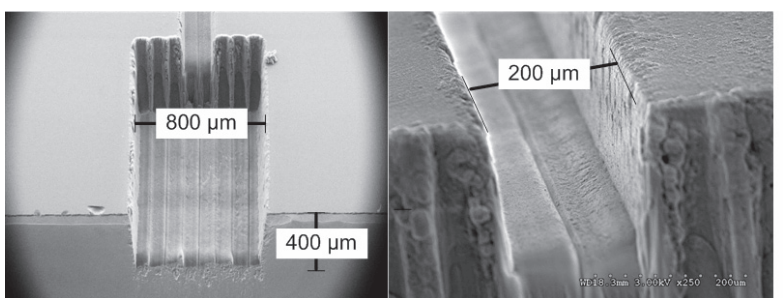

Figure 7. Laser milling on Pyrex realized with optimal parameters and circular beam overlap strategy $\left(F=6 \mathrm{~J} / \mathrm{cm}^{2}, f=100 \mathrm{~Hz}, V=170\right.$ $\mu \mathrm{m} / \mathrm{s}, N=40 \times 8$ for rectangular cavity, machining time: 3 hours).

\section{DISCUSSION}

The experimental optimization process shows that optimal parameters selection is independent of material properties, except for the laser energy level (fluence) needed to ablate adequately each material (see Figure 5). Recasts were observed for Si which seems to be ablated by melting and ejection of matter. This leads to poor machining results compare to Pyrex, PZT and even SiC. However, optimal machining parameters results in cleaner ablation wall for Si because less material is processed at each passage, at higher velocity and repetition rate with moderate fluence.

Less than half of initial machining time is now necessary to ablate all materials after the optimization of the process. Si cuts are generally wider at surface and wall taper is more important. This indicates that optical or mechanical properties influence the energy absorption and thermal dissipation during laser ablation process.

The mechanical and optical properties of tested materials are shown in Table II. 


\begin{tabular}{|c|c|c|c|c|c|}
\hline & \multicolumn{5}{|c|}{ Materials } \\
\hline Properties & Si & $\mathrm{SiC}$ & $\mathrm{Al}$ & PZT & Pyrex \\
\hline$\rho\left(\mathrm{kg} / \mathrm{m}^{3}\right)$ & 2300 & 3200 & 2700 & 7650 & 2230 \\
\hline $\mathrm{S}_{\mathrm{y}}(\mathrm{MPa})$ & 2000 & 2100 & 276 & $\begin{array}{c}80 \\
\text { (static) }\end{array}$ & - \\
\hline $\mathrm{E}(\mathrm{GPa})$ & 160 & 448 & 70 & 64 & 62.75 \\
\hline $\mathrm{k}(\mathrm{W} / \mathrm{m} . \mathrm{K}$ at $300 \mathrm{~K})$ & 156 & 490 & 236 & $\sim 1.1$ & 1 \\
\hline $\mathrm{C}_{\mathrm{p}}(\mathrm{J} / \mathrm{kg} . \mathrm{K})$ & 771 & 750 & 890 & 350 & 726 \\
\hline $\mathrm{k}=\mathrm{k} / \rho . \mathrm{C}_{\mathrm{p}}\left(\mathrm{cm}^{2} / \mathrm{s}\right)$ & 0.88 & 2.04 & 0.98 & 0.0041 & 0.0062 \\
\hline $\begin{array}{l}\mathrm{L}_{\mathrm{e}}=2(\mathrm{kt})^{1 / 2}(\mu \mathrm{m}, \mathrm{t}=5 \\
\mathrm{ns})\end{array}$ & 3.25 & 4.95 & 3.43 & 0.22 & 0.27 \\
\hline $\operatorname{CTE}\left(10^{-6} /{ }^{\circ} \mathrm{C}\right)$ & 2.62 & 4.2 & 25 & $4-6$ & 3.5 \\
\hline $\mathrm{T}_{\text {melting }}\left({ }^{\circ} \mathrm{C}\right)$ & 1410 & 3100 & 660 & 1250 & 820 \\
\hline $\mathrm{n}_{\mathrm{R}}(193 \mathrm{~nm})$ & 3.46 & 4.05 & 0.11 & - & 1.543 \\
\hline $\mathrm{n}_{\mathrm{I}}(193 \mathrm{~nm})$ & 2.75 & 1.42 & 2.17 & - & 0.077 \\
\hline $\mathrm{R}$ & $50 \%$ & $41.1 \%$ & $\sim 85 \%$ & - & $4.6 \%$ \\
\hline$\alpha^{-1}\left(10^{3} \mathrm{~cm}^{-1}\right)$ & 1769 & 1000 & 3000 & 125 & 48.4 \\
\hline$L_{o}$ or $\alpha^{-1}(\mu \mathrm{m})$ & 0.0057 & 0.01 & 0.0033 & $\begin{array}{l}0.08 \\
{[11]}\end{array}$ & 0.21 \\
\hline $\mathrm{Ke}=\mathrm{L}_{o} / \mathrm{L}_{e}$ & 0.002 & 0.002 & 0.001 & 0.364 & 0.765 \\
\hline Behavior (193 nm) & \multicolumn{3}{|c|}{$\begin{array}{l}\text { Metallic } \\
\text { Ke }<0.01\end{array}$} & \multicolumn{2}{|c|}{$\begin{array}{c}\text { Strong absorption } \\
0.01<\mathrm{Ke}<10 \\
\end{array}$} \\
\hline
\end{tabular}

Table II: Physical properties of materials for laser micromachining at $193 \mathrm{~nm}[\mathbf{1 1}, \mathbf{1 2}, \mathbf{1 3}]$.

A metric named $\mathrm{Ke}$ is defined as the ratio of the optical penetration length $\left(L_{o}\right)$ and the thermal penetration length $\left(L_{e}\right)$ [11] and gives an evaluation of the ablation behaviour of material for a given wavelength and pulse width. The $K e$ values in Table II indicate that $\mathrm{Si}, \mathrm{SiC}$ and $\mathrm{Al}$ exhibit metallic behaviour at $193 \mathrm{~nm}$ $(\mathrm{Ke}<0.01)$. Si and $\mathrm{Al}$ ablation mechanism is mainly a photothermal process which means that they melt and dissipate laser energy by thermal conduction. This explains why $\mathrm{Si}$ gives poor geometric results. On the other hand, Pyrex and PZT have strong absorption at $193 \mathrm{~nm}(0.01<K e<10)$ and ablation tends to be more a photochemical process. Their low thermal conductivity and high absorption combined to low melting point explain this behaviour. Absorbing energy and keeping it into the exposition zone helps elevating the local temperature to melt or vaporize material. Even if $\mathrm{SiC}$ requires high fluence compared to Pyrex and PZT, it appears to be a good candidate for laser micromachining at 193 $\mathrm{nm}$. While Si melts under the energy corresponding to $193 \mathrm{~nm}$, $\mathrm{SiC}$ directly vaporizes when it reaches the melting point (2400$3100{ }^{\circ} \mathrm{C}$ ). This leads to a slow but clean ablation.

More uniform beam energy could lead to better results for $\mathrm{Si}$ since the high peak energy of the Gaussian beam results in nonuniform machining depth. This aspect does not appear to be a problem for other materials that show strong absorption at $193 \mathrm{~nm}$ and poor thermal conductivity which leads to local machining and better depth control over the beam area.

As depicted in experimental results, typical cut widths ranging from $10 \mu \mathrm{m}$ to $100 \mu \mathrm{m}$ can be achieved with all materials. This is limited by optical system and laser energy. Wall angles could be at best estimated to $5^{\circ}$ and it seems possible to get deeper than $250 \mu \mathrm{m}$ (see Figure 4) with Pyrex, PZT and SiC. This allows high aspect ratio structures to be realized. The precision for cut width appears to be less than $5 \mu \mathrm{m}$. Depth precision could be as low as $0.25 \mu \mathrm{m}$ for $\mathrm{SiC}$ or PZT with low fluence. The machining precision could be improved further with better and faster measurement tools.

The excimer laser machining system seems to be a good alternative for rapid machining of MEMS materials for which precision in the order of $1-5 \mu \mathrm{m}$ is acceptable. Laser machining is faster than wet etching and DRIE for SiC and allows Pyrex, PZT and polymers machining. Among MEMS applications which can benefit from laser micromachining, bioMEMS on glass and polymers, PZT sensors and $\mathrm{SiC}$ high temperature sensors are good candidates. Even 3D surfaces are to be expected from laser micromachining in the next years with mask dragging techniques using excimer, high power DPSS and Copper vapor lasers $[\mathbf{2}, \mathbf{3}, \mathbf{6}]$.

\section{CONCLUSIONS}

The optimal parameters for excimer laser micromachining of $\mathrm{Si}$, Pyrex, PZT and SiC were identified from experimental data. Optimal parameters show that high repetition rate combined with high velocity workpiece dragging technique and laser fluence less than $20 \mathrm{~J} / \mathrm{cm}^{2}$ allow clean laser ablation at $193 \mathrm{~nm}$. Thin layer ablation of material is more efficient. Pyrex, PZT and SiC appear to be good candidates for excimer laser micromachining at $193 \mathrm{~nm}$ as opposed to Si for which material redeposition and melting make ablation difficult.

Various 3D geometries can now be ablated in order to complete conventional microfabrication techniques for MEMS prototyping. Further investigation of parameters interaction by the use the design of experiment method may be necessary to get better machining results.

\section{REFERENCES}

[1] M. Madou, "Fundamentals of microfabrication, The science of miniaturization", CRC Press (2002) 721 p.

[2] A. S. Holmes, "Excimer laser micromachining with half-tone masks for the fabrication of 3-D microstructures". IEE Proc., Sci. Meas. Technol., UK, 151(2) (2004) pp. 85-92.

[3] Y.-C. Lee, C.-M. Chen, and C.-Y. Wu, "A new excimer laser micromaching method for axially symmetric 3D microstructures with continuous surface profiles", Sensors and Actuators, A(117) (2005) pp. 349-55.

[4] N.H. Rizvi, P.T. Rumsby and M.C. Gower, "New developments and applications in the production of $3 \mathrm{D}$ microstructures by laser micromachining", Photonic Systems and Applications in Defense and Manufacturing, 1-3 Dec. 1999, Vol. 3898, SPIE-Int. Soc. Opt. Eng, Singapore (1999) pp. 240-9.

[5] J. Li and G. Ananthasuresh, "A quality study on the excimer laser micromachining of electro-thermal-compliant micro devices", Journal of Micromechanics and Microengineering, 11(1) (2001) pp. 38-47.

[6] M. Knowles, G. Rutterford, D. Karnakis, and A. Ferguson. "Micro-machining of metals, ceramics, silicon and polymers using nanosecond lasers", Technical report, Oxford Lasers Inc. (2005).

[7] B. Keiper, H. Exner, U. Löschner, and T. Kuntze, "Drilling of glass by excimer laser mask projection technique", J.Laser Appl., 12(5) (2000) pp.189-93.

[8] P. Dyer, "Excimer laser polymer ablation : twenty years on", Appl. Phys. A, Mater. Sci. Process. , A77(2) (2003) pp. 167-73.

[9] J. Jiang, C. Callender, J. Noad, R. Walker, S. Mihailov, J. Ding, and M. Day. "All-polymer photonic devices using excimer laser micromachining”, IEEE Photonics Technol. Lett. (USA), 16(2) (2004) pp. $509-511$

[10] A.A. Tseng, Y.-T. Chen, K.-J. Ma, "Fabrication of highaspect-ratio microstructures using excimer laser", Optics and Lasers in Engineering, 41(6) (2004) pp. 827-47.

[11] Basting D., "Excimer laser technology: laser sources, optics, systems and applications", Lambda Physik (2001) 292 p.

[12] E. Palik, "Handbook of optical constants of solids", Academic Press handbook series. Academic Press (1985).

[13] K. Hellwege, H. Landolt, and R. Börnstein, "LandoltBörnstein: Numerical Data and Functional Relationships in Science and Technology, new series: group III: crystal and solid state physics", Springer, (1980). 